\title{
BONE MICRODAMAGE AND CELL APOPTOSIS
}

\author{
Brendon Noble* \\ Musculo-Skeletal Research Unit, University of Edinburgh Medical School, Edinburgh, U.K.
}

\begin{abstract}
Accumulation of microdamage in bone leads to the reduced strength of our skeleton. In health, bone adapts to the prevailing mechanical needs of the organism and is also capable of self-repair, sensing, removing and replacing damaged or mechanically insufficient volumes of bone. In disease and old age these characteristics are reduced. In order to undertake both of the processes of functional adaptation and repair the bone resorbing and forming cells must be very accurately targeted to areas of physiological need. The mechanism by which cells are precisely targeted to areas requiring repair is both clinically relevant and poorly understood. The osteocyte has been assumed to play a role in sensing damage and signaling for its removal, due largely to its abundance throughout the mineralized bone matrix. However, until recently there has been little evidence that osteocyte function is modified in the vicinity of the microdamage. Here I outline the possibility that the targeted removal of bone containing microcracks might involve signals derived from the apoptotic death of the osteocyte. I shall discuss data that support or refute this view and will consider the possible molecular mechanisms by which controlled cell death might contribute to the signals for repair in the light of work involving cells in bone and other tissue systems.
\end{abstract}

Key Words: Osteocyte, apoptosis, microdamage, bone, osteoclast, signaling, targeted bone resorption.

\section{*Address for correspondence \\ B.S.Noble \\ Musculo-Skeletal Research Unit \\ University of Edinburgh Medical School \\ Teviot Place, Edinburgh EH8 9AG, UK}

Telephone Number: +441316502964

FAX: Number: +44 1316513077

E-mail: Brendon.Noble@ed.ac.uk

\section{Introduction}

Microdamage occurs in our bones as a result of repetitive cyclic loading incidents. Small cracks accumulate in the mineralised matrix of bone (Frost, 1960a) (Reilly and Currey, 2000) in a broadly mechanical load dependent manner (Schaffler et al., 1989). The result is that in a set time interval an increased number of cracks will be engendered in the load bearing bones of individuals who undertake high impact exercise than in those that are relatively sedentary (Devas, 1961; Brukner et al., 1966; McBryde, 1975; Cline et al., 1998; Nunamaker et al., 1990). This phenomenon is common to any load bearing material subjected to repetitive stresses that are high but lower than failure stress. However, unlike most engineering materials bone is capable of removing accumulating microdamage through the targeted action of its effector cells (osteoclasts and osteoblasts) (Burr et al., 1985; Burr and Martin, 1993; Mori and Burr, 1993; Burr, 2001; Parfitt, 2001). Unfortunately there appears to be an age and gender related accumulation of microdamage in our load bearing bones (Schaffler et al., 1995a). These observations are consistent with the existence of a mechanism by which damage is targeted in bone and also to the development of an age related lesion in this mechanism. While it has been recognised for some time that there must be a method by which damage is sensed and targeted for removal by osteoclastic activity (Frost, 1985) our understanding of the cellular and molecular mechanisms involved in this process are poor. In addition, the reasons for the impairment of the targeting system with subject age are largely unknown.

Here we will discuss more recent findings which point to the role of the osteocyte and more specifically the apoptotic death of these cells in the mechanism by which osteoclasts sense and target damage in bone.

\section{Apoptosis - 'Death before Dishonour'}

The identification of apoptotic cell death as an energy-dependent, non-immunogenic (non-phlogistic) and potentially controllable process has completely changed the way that we view cell destruction. It is clear to us now that the death of a cell does not necessarily signify a problem in a body system since it may occur as an entirely normal "healthy" component of the lifetime repertoire of a cell or tissue. It may also occur as a strategic response to a stimulus that may engender damaging effects in the future such as those modifying our genetic material (Evan and Littlewood, 1998) or to restrict the locality of specific cell phenotypes through adhesion receptor/ligand interactions, (known as anoikis) (Frisch and Francis, 1994; Frisch et 


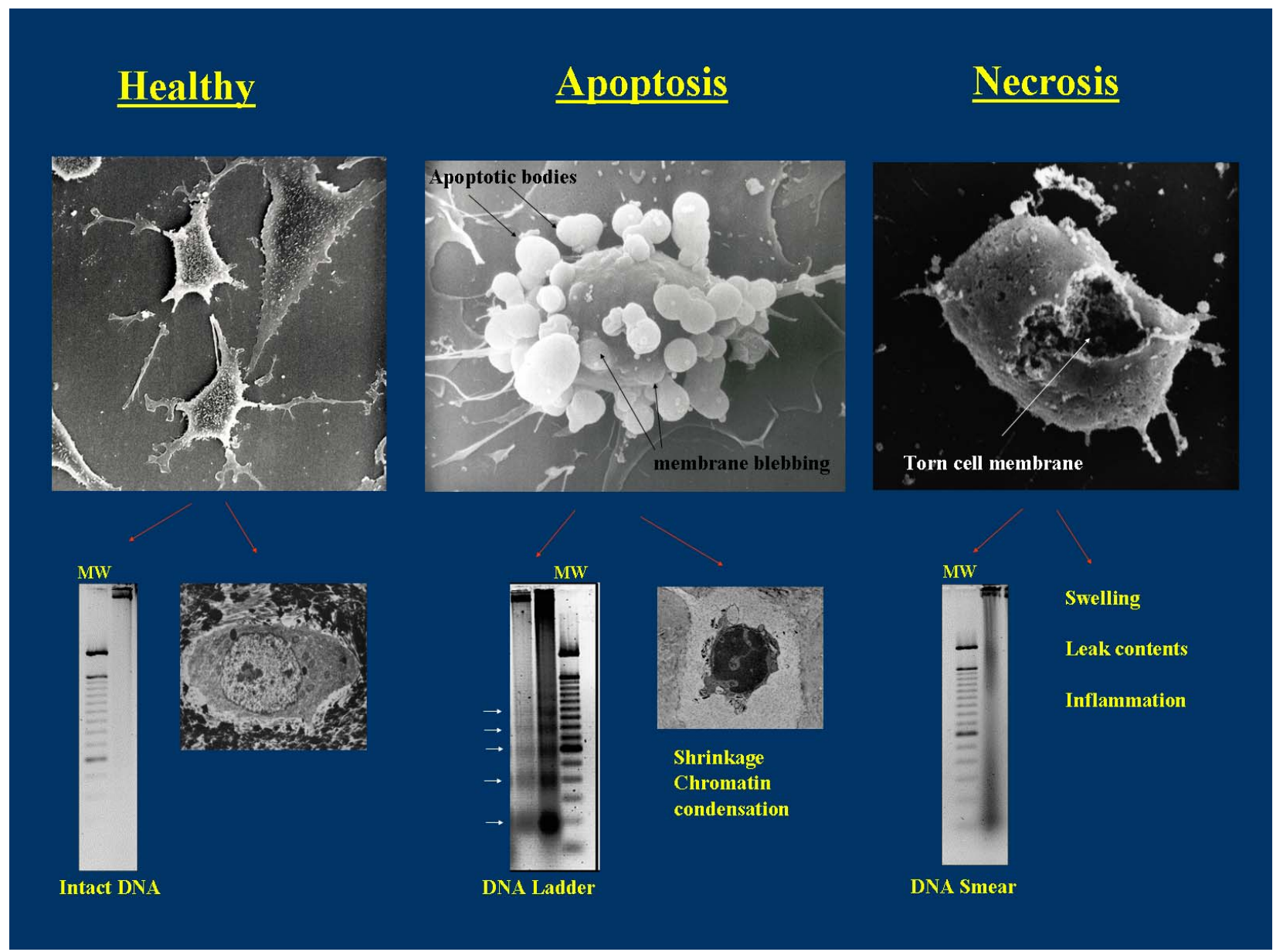

Figure 1. Some morphological molecular characteristics of healthy apoptotic and necrotic osteocytes. Scanning electron microscopy (EM) images show morphological characteristics of the MLO-Y4 osteocyte cell line in culture after stimulation with inducers of death. Gel electrophonesis of DNA extracted from human tissues show intact DNA, apoptotic DNA ladders caused by regular inter-nucleosomal fragmentation and neurotic DNA smear caused by massive random fragmentation of DNA in these cells. Transmission EM shows morphological characteristics of normal and apoptotic cells demonstrating nuclear condensation and cell shrinkage in lacunae.

al., 1996). Biologists have only recently become accepting of an essentially wasteful system in which cells willingly undergo suicide in the interest of the whole organism. But apoptosis should not simply be viewed as the deletion of cells since the death process gives rise to a large and expanding number of potent signal molecules that dramatically affect the behaviour of cells in the vicinity of the deletion and potentially far beyond.

The process of apoptosis involves an orchestrated cell shrinkage, retention of organelles, chromatin condensation and margination, nuclear membrane changes, protein fragmentation, cell membrane modification and cleavage of DNA often into inter-nucleosomal size increment fragments (Wyllie et al., 1980). This is followed by packaging of the cell's cytoplasmic and nuclear contents into membrane bound vesicles with specific membrane surface molecular signatures which allow their rapid removal from the system by specialist and amateur phagocytic cells (for review see Hengartner, 2000). The packaging of cellular contents into vesicles (apoptotic bodies) and their rapid removal from the system allows apoptosis to occur with minimal or no associated inflammatory response. Central to the initiation and execution of the apoptotic cascade are a number of enzymes that contribute to the demolition of specific cellular components and structures, destruction of inhibitors of apoptosis and activation of stimulators of the same. The most prominent of these are cysteine proteases of the caspase family. At least 8 of these enzymes are involved in the apoptotic process including the production of the signature morphological changes (for review see Hengartner, 2000).

The morphological criteria describing apoptosis remain the only certain evidence of an apoptotic death. Many of the biochemical and molecular changes such as caspase activation, DNA ladders, phoshatidylserine exposure and membrane integrity may also present to a lesser extent during necrosis. For this reason they should be used as a method of apoptosis identification only in combination and preferably along with a morphological test.

Necrosis is the alternative method of cell death involving cell swelling and bursting which results in spillage of cell contents and (see Figure 1) related initiation of an inflammatory response via neighbouring cell types and cells of the immune system (Wyllie et al., 1980; Wyllie, 1997). 
Necrosis is not energy dependent, is rapid and not as susceptible to control as apoptosis. Thankfully it is not as common as apoptosis which accounts for the vast majority of the estimated 10 billion cell deaths that occur daily in a healthy individual (Heemels, 2000).

Cells are removed specifically and efficiently when they are supernumerary, damaged or misplaced. For example cells undergo apoptosis upon experiencing moderate levels of physical injury or infection (Martin, 2001; Dockrell, 2001; Grassme et al., 2001), after initiation of oncogenic transformation (Nguyen-Ba and Vasseur, 1999; Compagni and Christofori, 2000) radiation induced damage (Kulms and Schwarz, 2002), as a result of removal of nutrients (Hogg et al., 1999), growth factors or hormones key to their function (Fraser et al., 1996; Pelengaris and Evan, 1997; Deckwerth et al., 1998; Monroe et al., 2000; Tesarik et al., 2002), or when they have been developmentally programmed for removal during tissue morphogenesis (Meier et al., 2000). In addition, some cells die by apoptosis as a normal response to having finished a time or activity limited bout of differentiated function (Adams and Shapiro, 2002), to maintain or modify the size/shape of organs and simply to counter the huge number of cell mitoses in the adult organism (i.e., turnover at the cellular and tissue level) (Kerr et al., 1972).

Clearly the ultimate outcome of cellular apoptosis is the death of a cell resulting in the removal of the cell, it's genetic material and associated activities from a tissue. However, the cell does not disappear without potentially having profound effects on neighbouring cell types who are often recruited in the removal of the apoptotic vesicles (Savill and Fadok, 2000) or which might rarely undergo 'bystander apoptosis' (Andrade-Rozental et al., 2000; Ripps, 2002; Sanson et al., 2002).

Macrophages are the professional phagocytes in our bodies. They respond differently to the ingestion of an apoptotic cell vesicle than to necrotic cell debris. While necrotic cell material engenders the production of pro-inflammatory cytokines such as TNF- $\alpha$ by the phagocyte, the same cell will produce anti-inflammatory molecules such as TGF- $\beta 1$, PGE-2 and IL-10 and induce macrophage release of thromboxane B2 (Voll et al., 1997; Fadok et al., 1998, 2000), upon encountering and ingesting an apoptotic body (Savill and Fadok, 2000). The result is that apoptosis is not simply non-stimulatory to the immune system but is also inhibitory to it. A specific system of apoptotic cell recognition must exist.

The cell membrane of the apoptotic cell is known to expose a range of molecules that are thought to constitute a unique "apoptotic" signature recognised by phagocytic cells. These include a loss of phospholipid asymmetry (Fadok et al., 2001), expression of the adhesion molecule ICAM-3 (Moffatt et al., 1999; Gregory, 2000) surface sugars (Duvall et al., 1985; Dini et al., 1992)), and oxidised phospholipid surface structures (Chang, 1999). Thrombospondin, complement components and $b(2)$ glycoprotein I contribute to the process in some way by bridging the phagocyte and apoptotic-cell surfaces (Stern et al., 1996).

In addition, receptors and ligands on the phagocyte surface have been implicated in the recognition and engulfment of apoptotic cells. These include lectins (Ii et al., 1990;
Beppu, 2001), scavenger receptors (Kulms and Schwarz, 2002), the ATP-binding cassette transporter 1 (ABC1) (Luciani and Chimini, 1996; Wu and Horvitz, 1998; Hamon et al., 2000), integrins (Stern et al., 1996; Rubartelli et al., 1997) the lipopolysaccharide (LPS) receptor CD14 (Gregory, 2000) and complement receptor (CR)3 and CR4 (Mevorach et al., 1998; Taylor et al., 2000). The role and function served by these receptors and the exact molecular pairings required for function are largely unknown.

Disruption of this complex system of cell removal leads to a small number of significant disease states and developmental abnormalities such as systemic lupus erythematosus (SLE) and Behcet's disease (Yang et al., 2002). But, there is a high level of redundancy in the apoptotic system, such that disruption of many key molecular elements in the process (e.g., some caspases) fails to engender a phenotype (Ueki et al., 2002). Overall then apoptosis is important to the health of our bodies is often enhanced during disease and injury and is relatively difficult to abolish.

\section{Bone and Apoptosis}

In theory bone is potentially unique with regard to its ability to withstand loss of cells particularly the matrix bound osteocytes. Unlike soft tissues the loss of significant numbers of cells in bone will not have an immediate impact on the size and mechanical function of the tissue. In the medium term profound changes in bone function would almost certainly ensue but this tissue would seem to be an ideal site for showcasing the signalling power of apoptosis. Could apoptosis play a role in targeted remodelling in bone?

\section{The causes and outcome of microdamage.}

High impact, intensive exercise has been shown to engender microdamage in bones. For example, significant levels of microdamage can be found in the ribs of rowers (Warden et al., 2002), the long bones of race horses (Norrdin et al., 1998), the leg experiencing the highest loads in greyhounds running on oval tracks in a common direction (Muir et al., 1999; Tomlin et al., 2000) and associated with the 'march fractures' of army recruits undertaking intensive training (McBryde, 1975). However it has also been shown that strains magnitudes of $1500 \mu$ strains which equate to osteogenic levels of exercise (Burr et al., 1996) are sufficient to cause microdamage within 10,000 cycles (Burr, 2001) and predicted to causes stress failure at $10^{5}$ cycles (Taylor, 1998). In addition several studies have shown strong relationships between increased age of an individual and exponential increase in crack density (Schaffler et al., 1995a).

Accumulation of microdamage has been shown to reduce the strength of bones. While the existence of microdamage in a bone appears to decrease its stiffness probably due to dissipation of energy, the overall strength or force to failure can be reduced dramatically (Carter and Hayes, 1977). This phenomenon clearly has direct clinical relevance. 


\section{Targeted removal of microdamage?}

It has been suggested that removal of microdamage in bone is not achieved through a 'random' stochastic remodelling process alone but that damage is actively targeted for removal by the osteoclast population (Burr and Martin, 1993; Parfitt, 2001). Evidence to support this hypothesis has been produced by the group of Burr in which they found that osteoclastic activity was over represented at sites of microdamage (Burr et al., 1985; Mori and Burr, 1993). Recent experiments demonstrating the time dependent migration of osteoclasts into regions of cortical bone containing experimentally induced microdamage in rats have strengthened the argument for the targeting of damage in bone (Verborgt et al., 2000; Noble et al., 2003). Coupled with the knowledge that high levels of microdamage can increases fracture risk these data point to the importance of the bone effector cell targeting system in the maintenance of bone health.

\section{How does the targeting system work?}

The mechanism by which microdamage is targeted in bone is unknown as is the reason for its loss under conditions of ageing and disease. We might find clues as to the mechanism by examining the changes in bone cell behaviour known to be associated with conditions under which the targeting system is lost or impaired (Figure 2).

In this regard, while targeting of damage appears to be sufficient for maintenance of strength in healthy bone, osteoclast targeting of damage does not appear to work efficiently in older individuals (Frost, 1960a; Wong et al., 1985; Schaffler et al., 1995a,b; Norman and Wang, 1997; Mori et al., 1997). More specifically damage is not efficiently removed from interstitial volumes which are representative of older regions of bone (Wong et al., 1985). Accumulation of microdamage is higher in females than males and there is a particularly marked increase in women over the age of 40 years (Schaffler et al., 1995a). High doses of bisphoshonates also reduce the removal of microdamage (Hirano et al., 2000; Mashiba et al., 2000; Li et al., 2001; Mashiba et al., 2001) due to their obvious inhibitory effects on osteoclast function.

The reasons for the enhanced accumulation of microdamage under these circumstances is not entirely clear but is likely to be due to one of two broadly defined changes in the bone. Firstly, a change in the material properties of the bone that leads to accumulation of damage that is beyond the scope of the repair system. Secondly a problem with the cells involved in the sensing, signalling and/or repair of the bone. In fact it is likely that both of these changes contribute to the accumulation of damage but overall, that any changes in the material properties of the bone will not occur entirely independently of changes in the cell population that create, remodel and maintain it.

Cell behaviour is likely to represent a significant contributory factor in this phenomenon. Cells might lose their ability to produce the stimulus, their sensitivity to the targeting stimulus or their ability to respond to it, or there may be changes in detailed cell function such as synthesised collagen composition, resorptive enzyme activities or their numbers in bones.

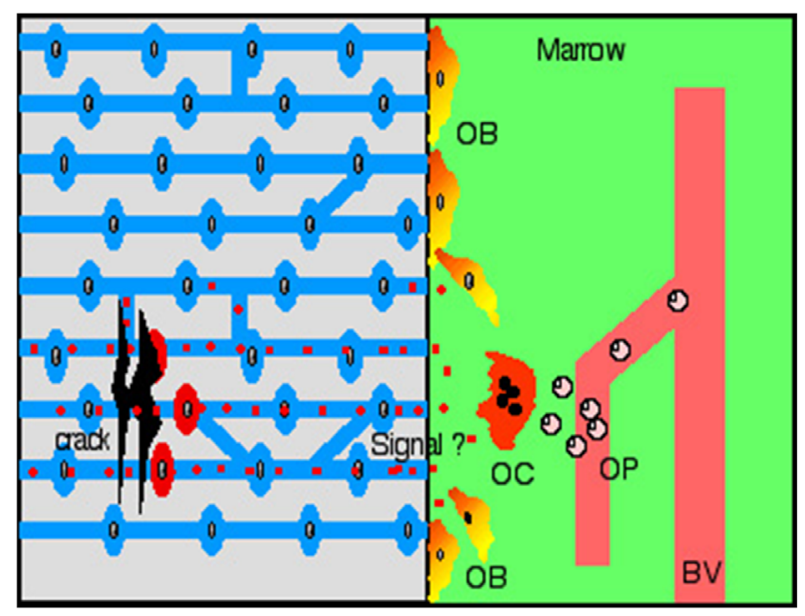

Figure 2. A signal must be produced near to the site of microdamage in order for osteoclast (OC) production from blood vessel (BV) derived osteoclast progenitors (OP) to be initiated in a site-specific manner. Secondary signals may be derived from osteoblasts (OB), which are thought to vacate the bone surface prior to resorption.

Age related changes in the behaviour and dynamics of bone cell populations are likely numerous and to a large extent understudied. Gaining an understanding of altered cell behaviour is difficult since it appears that after a prepubertal period of longitudinal growth our bones spend a number of years expanding in width (late teens through 20's) only to embark on a slow but largely unavoidable loss of material from the age of 30 yrs onwards (Parfitt, 1994). Not only does this mean that there is never really a "steady state" situation within which to describe the 'normal' compliment and activity of cells in bone but also that it is unlikely that remodelling ever functions merely to remove and accurately replace an existing piece of bone. A state of disequilibrium exists.

The postmenopausal reduction in circulating oestrogen levels is associated with increased rates of bone turnover and bone loss due to a relatively high activity and numbers of both osteoblasts and osteoclasts with a functional imbalance in favour of the osteoclasts (Rosen, 2000). The large increase in osteoclastic activity that occurs after withdrawal of oestrogen is transient and activity returns to levels close to those in oestrogen-replete individuals with time (Lane et al., 1998; Tremollieres et al., 2001). The increased osteoclast activity would tend to coincide with the occurrence of increased numbers of microcracks in these individuals although the detailed timing of the two phenomenon has not been compared.

Changes in the numbers and activity of bone cells with ageing is less clearly understood possibly due to the unfortunate decreased popularity of histomorphometric studies in bone research. Studies have variously described significant increases or decreases with age (Gruber et al., 1986; Rodan and Martin, 2000; Chan and Duque, 2002). Overall, it would seem fair to suggest that osteoblast activity is likely reduced and that osteoclast activity is either increased or remains constant with age and that osteoblast function in the absence of osteoclastic activity cannot remove and 
replace microdamage although more precise study is required in this field.

Clearly, there is not a consistent and obvious problem with generalised osteoclastic function associated with an increased occurrence of cracks, perhaps supporting the notion that it is targeted osteoclast activity that is important in the removal of microdamage. It is possible that any lesion is associated with the cells that are sensing the damage. The site of the damage-sensor in bone is not clear but the matrix bound osteocytes are favoured since they are the only cells consistently to be found in close association with damage.

\section{The Osteocyte}

The osteocyte is formed from a differentiated osteoblast that is present on an active bone-forming surface and which has for a particular but unknown reason ceased production of bone matrix. In doing so, it falls behind its neighbours who are advancing with the newly formed bone surface while remaining in intimate contact with the advancing cells via long cellular projections (Marotti et al., 1998). It becomes embedded in the bone matrix in a vacuole cushioned by fluid and large molecules with the appearance of glycosaminoglycans. Only one in approximately 12 osteoblasts undergo this radical change in behaviour and they are all sitting on a bone surface next to a cell which will not behave in this way. There must exist a highly controlled message that brings about the change in a very localised fashion. The behaviour does not appear to be an entirely genetically programmed 'patterning' response. Despite the fact that lacuna density does scale inversely with body size across species (Mullender et al., 1996a) the density of lacunae is found to be variable not only between individuals (Tomkinson 1998) and with age (Mullender et al., 1996a), but also under conditions of disease (Tomkinson 1998) and altered mechanical stimuli (Mullender et al., 1996b).

There is no doubt that the osteocyte is responsive to load. The cells respond in vitro and in vivo to increased load induced strains by producing or modifying a number of important molecules such as activation of ion channels (Rawlinson et al., 1995), upregulation of Fos gene expression (Inaoka et al., 1995), nitric oxide (Pitsillides et al., 1995; Klein-Nulend et al., 1995), prostocyclin production (Lanyon, 1992), IGF-1 (Lean et al., 1995) and release of PGE-2 (Ajubi et al., 1996), collagen I gene expression (Sun et al., 1995), COX-2 (Matsumoto et al., 1998), decreased glutamate transporter expression (Mason et al., 1997) and increased intracellular calcium (Rawlinson et al., 1995; Kawata et al., 1998). However, few of these responses have been shown to be a requirement of the loading response at the level of the whole bone and none have been shown to be a required product of the osteocyte population specifically.

\section{During ageing what happens to the osteocyte?}

The long held view that the majority of osteocytes live for the entire life-span of an individual was based primarily on findings in the bone of the ear ossicle. Because viable osteocytes can be found in the ear ossicle and labyrinthine capsule of aged individuals and this bone was considered to experience little if any remodelling the osteocytes were believed to have been 'born' at the point of production of the bone. In fact it is true that the bone experiences only a little remodelling after the age of 1 year. However, the interpreters of this data have failed to acknowledge that the data also demonstrates that in individuals over 1 year of age $40-60 \%$ of osteocytes are already dead and that 90 $95 \%$ of the cells are dead from age 30 years and older (Kakizaki and Altmann, 1971; Marotti et al., 1998). The remaining $5-10 \%$ of cells that are viable could be the result of the small amount of remodelling that does occur on the surfaces of these bones. In the context of this article it will be important to remember that the lack of osteocytes in this bone coincides with a lack of remodelling activity. It has been clear for some time that the numbers of viable osteocytes in our bones decreases with age (Frost, 1960b; Dunstan et al., 1993). It is likely that the majority of this age related decrease is occurring in the increasing proportion of older bone that is not being actively remodelled (i.e., the interstitial bone) in older individuals (Chan and Duque, 2002).

Overall, the loss of osteocytes from our bones is associated with a generalised impairment of the damage repair system. Older people have more damage, more damage is found in older and less vital interstitial bone and importantly regions of bone with lower osteocyte lacuna density contain more damage (see above).

\section{What is the nature of the signal?}

If a micro-damage "targeting" signal is derived from the osteocyte we might expect to observe a change in osteocyte behaviour, which co-localises with damaged bone and with resorption sites.

The signal mechanism may involve either the gain of a pro-resorptive signal or the loss of an inhibitor of osteoclast function. Previous studies demonstrating increased accumulation of damage in regions of low osteocyte number (Mori et al., 1997) and illustrating reduced remodelling of bone devoid of live osteocytes in the ear ossicle (Marotti et al., 1998), labyrinthine capsule (Kakizaki and Altmann, 1971), transplanted bone in the rat (Kamijou et al., 1994) and human osteonecrotic bone (Kenzora et al., 1978) and production of a pro-osteoclastic signals form an osteocyte cell line (Zhao et al., 2002) all point to the greater likelihood of a pro-resorptive signal of osteocytic origin being involved. On the other hand a small number of studies have identified osteocyte cell fractions and osteocyte derived molecules with negative effects on osteoclast formation and function although the relevance of these data in vivo are as yet unclear (Maejima-Ikeda et al., 1997; Heino et al., 2002).

\section{Osteocyte apoptosis during induction of microdamage}

Recently it has been demonstrated that induction of damage in bone is associated with an increase in osteocyte death by apoptosis. Large-scale osteocyte apoptosis has been associated with the cortical bone resorption induced by mechanical load engendered microdamage in a rat model of 
fatigue fracture (Noble et al., 1997b; Verborgt et al., 2000; Noble et al., 2003). Under healthy circumstances little if any intracortical remodelling occurs in rat long bones but if microdamage is generated in the cortical bone, osteoclasts enter the cortical bone to remove the damage. In both studies, damage was induced through overloading the bones (using cyclical loads at approximately $8000 \mu$ strain) and osteoclastic invasion and osteocyte apoptosis was monitored on a spatial and temporal basis. A transient burst of osteocyte apoptosis at 7 days after damage induction was shown to precede osteoclastic invasion by several days (Noble et al., 2003) and to co-localise with regions of damaged bone (Verborgt et al., 2000). At 14 days after damage induction the apoptosis had resulted in a reduction in live osteocyte numbers. However, resorbed bone was replaced by newly formed bone by 28 days after the damage-inducing incident. The increase in apoptosis at damage sites was associated with an increase in the proapoptotic molecule bax (Verborgt et al., 2000). The fact that apoptosis was associated with regions of damage and that it preceded osteoclastic activity raises the possibility that the apoptotic event might actually represent the source of a signal used in targeted osteoclastic invasion.

Recent evidence from other studies illustrates an association between situations of bone modelling and remodelling and osteocyte apoptosis. Apoptotic osteocytes are more common in young growing bone experiencing a high degree of resorption than in relatively quiescent normal adult human bone (Noble et al., 1997b). The increase in bone turnover induced during a medical menopause is associated with an increase in the proportion of apoptotic and dead osteocytes in human bone (Tomkinson et al., 1997) and similar increases could be prevented through the addition of $17 \beta$-estradiol in ovarectomised rats (Tomkinson, 1998). Studies have shown that glucocorticoid induced bone loss in the mouse and human is associated with increased osteocyte apoptosis (Weinstein et al. 1998, 2000). In contrast, a study in the rat was unable to demonstrate increased apoptosis of osteocytes after glucocorticoid treatment (Silvestrini et al., 2000) and might be of relevance to the known species specific responses to these compounds. There is also other evidence of co-localisation of the osteocyte apoptosis and osteoclastic resorption. In a rat model of bone loading, the proportion of apoptotic osteocytes present in the ulna cortex adjacent to a known resorption site was halved after a period of loading that resulted in switching off the resorption site (days (Noble et al., 2003)). By loading these bones both osteocyte apoptosis and bone resorption were switched off in the same region of bone. Furthermore, in this model apoptotic osteocytes were more common in regions of bone experiencing very low peak strain magnitudes.

All of these situations of high apoptosis involve high levels of bone (re)modelling and in particular resorption. These observations would tend to suggest that osteocyte apoptosis plays a role in the normal bone turnover process itself, that oestrogen is an important determinant of osteocyte viability and that strain also acts as a survival factor in bone. The possibility that loading affects osteocyte viability is backed up by experiments ex-vivo in which loading of rat bones in culture increased viability of the osteocytes (Lozupone et al., 1996).

The appearance of osteocyte apoptosis in bone that is undergoing turnover and more specifically increased resorption poses the question as to the identity of molecular links between the two processes. In other cell types, apoptosis involves the production of signal molecules that initiate the removal of the cell by phagocytosis. The cells undertaking the phagocytosis are often not 'professional phagocytes' but can be neighbouring cells. Since only the osteoclast could efficiently remove apoptotic osteocytes in mineralised matrix, it is possible that signals produced by apoptotic cells may influence osteoclast formation and/or function - either directly or indirectly. The search for the identity of such molecules is underway.

The mechanism of initiation of apoptosis by microdamage might be related to either mechanically sensitive signalling pathways or direct physical damage to either the cells or the lacuna/canalicular system that supplies them with nutrients and oxygen.

Both epithelial and cardio-myocyte cells are known to respond to high levels of stretch by undergoing apoptosis engendered through the induction of P53, angiotensin II and FAS-ligand (Leri et al., 1998; Wang et al., 1999). On the other hand plasma membrane stress failure can lead to cell death. However, many cells display a remarkable capacity to survive membrane rupture through the its rapid repair by fusion of lysosomal vesicles (McNeill, 2002) and healthy muscle skeletal tissue may contain up to $30 \%$ wounded cells (McNeill and Steinhardt, 1997). Further work is required to determine the mechanism by which microdamage induces osteocyte apoptosis.

The potential molecular links between damage induced apoptosis and targeted osteoclast activity are unknown and are the subject of research in our laboratories. However the identification of osteocyte apoptosis as a potential signal source has improved our chances of identifying the signals central to the targeted resorption process in bone and the design of methods of minimising or controlling the production of these signals.

\section{References}

Adams CS, Shapiro IM (2002) The fate of the terminally differentiated chondrocyte: evidence for microenvironmental regulation of chondrocyte apoptosis. Crit Rev Oral Biol Med 13: 465-473.

Ajubi NE, Klein-Nulend J, Nijweide PJ, VrijheidLammers T, Alblas MJ, Burger EH (1996) Pulsating fluid flow increases prostaglandin production by cultured chicken osteocytes - A cytoskeleton-dependent process. Biochem Biophys Res Commun 225: 62-68.

Andrade-Rozental AF, Rozental R, Hopperstad MG, Wu JK, Vrionis FD, Spray DC (2000) Gap junctions: the "kiss of death" and the "kiss of life". Brain Res Rev 32: 308315.

Beppu M (2001) Mechanism of removal of aged cells, oxidized cells and apoptotic cells through carbohydrate chains. Seikagaku 73: 196-200.

Brukner P, Bradshaw C, Khan KM, White S, Crossley 
K (1966) Stress fractures: a review of 180 cases. Clin J Sports Med 6: 85-89.

Burr DB (2001) Targeted and non-targeted remodeling. Bone 30: 582-584.

Burr DB, Martin RB, Schaffler MB, Radin EL (1985) Bone remodeling in response to in vivo fatigue microdamage. J Biomech 18: 189-200.

Burr DB, Martin RB (1993) Calculating the probability that microcracks initiate resorption spaces. J Biomech 26: 613-616.

Burr DB, Milgrom C, Fyhrie D, Forwood M, Nyska M, Finestone A, Hoshaw S, Saiag E, Simkin A (1996) In vivo measurement of human tibial strains during vigorous activity. Bone 18: 405-410.

Carter DR, Hayes WC (1977) Compact bone fatigue damage - I Residual strength and stiffness. J Biomech 10: 325-327.

Chan G, Duque G (2002) Age-related bone loss: old bone, new facts. Gerontology 48: 62-71.

Chang MK, Bergmark C, Laurila A, Horkko S, Han KH, Friedman P, Dennis EA, Witztum JL (1999) Monoclonal antibodies against oxidized low-density lipoprotein bind to apoptotic cells and inhibit their phagocytosis by elicited macrophages: evidence that oxidation-specific epitopes mediate macrophage recognition. Proc Natl Acad Sci USA 96: 6353-6358.

Cline AD, Jansen GR, Melby CL (1998) Stress fractures in female army recruits: implications of bone density, calcium intake and exercise. J Am Coll Nutr 17: 128-135.

Compagni A, Christofori G (2000) Recent advances in research on multistage tumorigenesis. Br J Cancer 83: 1-5.

Deckwerth TL, East RM, Knudson CM, Korsmeyer SJ, Johnson EM Jr (1998) Placement of the Bcl2 family member bax in the death pathway of sympathetic neurons activated by trophic factor deprivation. Exp Neurol 152: 150162.

Devas MB (1961) Compression stress fractures in man and the greyhound. J Bone Joint Surg 43B: 540-551.

Dini L, Sutuori F, Lentini A, Oliverio S, Piacentini M (1992) The clearance of apoptotic cells in the liver is mediated by the asialo-glycoprotein receptor. FEBS Lett 296: 174-178.

Dockrell DH (2001) Apoptotic cell death in the pathogenesis of infectious diseases. J Infect 42: 227-234.

Dunstan CR, Somers NM, Evans RA (1993) Osteocyte death and hip fracture. Calcif Tissue Int 53: S113-S118.

Duvall E, Wyllie AG, Morris RG (1985) Macrophage recognition of cells undergoing programmed cell death (apoptosis). Immunology 56: 351-358.

Evan G, Littlewood T (1998) A matter of life and cell death. Science 281: 1317-1322.

Fadok VA, Bratton DL, Konowal A, Freed PW, Westcott JY, Henson PM (1998) Macrophages that have ingested apoptotic cells in vitro inhibit proinfammatory cytokine production sthrough autocrine/paracrine mechanisms involving TGF- $\beta$, PGE2 and PAF. J Clin Invest 101: 890898.

Fadok VA, Bratton DL, Rose DM, Pearson A, Ezekewitz RA, Henson PM (2000) A receptor for phosphatidylserinespecific clearance of apoptotic cells. Nature 405: 85-90.
Fadok VA, de Cathelineau A, Daleke DL, Henson PM, Bratton DL (2001) Loss of phospholipid asymmetry and surface exposure of phosphatidylserine is required for phagocytosis of apopotic cells by macrophages and fibroblasts. J Biol Chem 276: 1071-1077.

Fraser A, McCarthy N, Evan GI (1996) Biochemistry of cell death. Curr Opin Neurobiol 6: 71-80.

Frisch SM, Francis H (1994) Desruption of epithelial cell-matrix interactions induces apoptosis. J Cell Biol 124: 619-626.

Frisch SM, Vuori K, Ruoslahti E, Chan-Hui PY (1996) Control of adhesion-dependent cell survival by focal adhesion kinase. J Cell Biol 134: 793-799.

Frost HM (1960a) Presence of microscopic cracks in vivo in bone. Henry Ford Hospital Med Bull 8: 25-35.

Frost HM (1960b) In vivo osteocyte death. J Bone Joint Surg 42: 138-143.

Frost HM (1985) Bone microdamage: Factors that impair its repair. In: Current Concepts of Bone Fragility. Uhtofff HD (ed). Springer-Verlag, Berlin. pp 123-148.

Grassme H, Jendrossek V, Gulbins E (2001) Molecular mechanisms of bacteria induced apoptosis. Apoptosis 6: 441-445.

Gregory CD (2000) CD14-dependent clearance of apoptotic cells: relevance to the immune system. Curr Opin Immunol 12: 27-34.

Gruber HE, Ivey JL, Thompson ER, Chesnut CH 3rd, Baylink DJ (1986) Osteoblast and osteoclast cell number and cell activity in postmenopausal osteoporosis. Miner Electrolyte Metab 12: 246-254.

Hamon Y, Broccardo C, Chambenoit O, Luciani MF, Toti F, Chaslin S, Freyssinet JM, Devaux PF, McNeish J, Marguet D, Chimini G (2000) ABC1 promotes engulfment of apoptitic cells and transbilayer redistribution of phosphatidylserine. Nat Cell Biol 2: 399-406.

Heemels M (2000) Nature Insight: Apoptosis. Nature 407: 769 .

Heino TJ, Hentunen TA, Vaananen HK (2002) Osteocytes inhibit osteoclastic bone resorption through transforming growth factor-beta: enhancement by estrogen. J Cell Biochem 85: 185-197.

Hengartner MO (2000) The biochemistry of apoptosis. Nature 407: 770-776.

Hirano T, Turner CH, Forwood MR, Johnston CC, Burr DB (2000) Does suppression of bone turnover impair mechanical properties by allowing microdamage accumulation. Bone 27: 13-20.

Hogg N, Browning J, Howard T, Winterford C, Fitzpatrick D, Gobe G (1999) Apoptosis in vascular endothelial cells caused by serum deprivation, oxidative stress and transforming growth factor-beta. Endothelium 7: 3539.

Ii M, Kurata H, Itoh N, Yamashima I, Kawasaki T (1990) Molecular cloning and sequence analysis of cDNA encoding the macrophage lectin specific for galactose and $\mathrm{N}$ acetylgalactosamine. J Biol Chem 265: 11295-11298.

Inaoka T, Lean J, Bessho T, Chow J, Mackay A, Kokubo $\mathrm{T}$ (1995) Sequential analysis of gene expression after an osteogenic stimulus: $c$-fos expression is induced in osteocyes. Biochem Biophys Res Commun 217: 264-270. 
Kakizaki I, Altmann F (1971) The osteocytes of the labyrinthine capsule. Arch Otolaryng 94: 139-149.

Kamijou T, Nakajima T, Ozawa H (1994) Effects of osteocytes on osteoinduction in the autogenous rib graft in the rat mandible. Bone 15: 629-637.

Kawata A, Miyauchi A, Kikuni-Takagaki Y (1998) Mechanisms of bone formation in vitro by stretched osteocytes. Jap J Med Electronics Biol Eng 36: 252-258.

Kenzora JE, Steele RE, Yosipovitch ZH, Glimcher MJ (1978) Experimental osteonecrosis of the femoral head in adult rabbits. Clin Orthop 130: 8-46.

Kerr JF, Wyllie AH, Currie AR (1972) Apoptosis: a basic biological phenomenon with wide-ranging implications in tissue kinetics. Br J Cancer 26: 239-257.

Klein-Nulend J, Semeins CM, Ajubi NE, Nijweide PJ, Burger EG (1995) Pulsating fluid flow increases nitric oxide (NO) synthesis by osteocytes but not periosteal fibroblasts - Correlation with prostaglandin upregulation. Biochem Biophys Res Commun 217: 640-648.

Kulms D, Schwarz T (2002) Molecular mechanisms involved in UV-induced apoptotic cell death. Skin Pharmacol Appl Skin Physiol 15: 342-347.

Lane NE, Thompson JM, Haupt D, Kimmel DB, Modin G, Kinnery JH (1998) Acute changes in trabecular bone connectivity and osteoclast activity in the ovariectomized rat in vivo. J Bone Miner Res 13: 229-236.

Lanyon LE (1992) Control of bone architecture by functional load bearing. J Bone Miner Res 7: S369-S375.

Lean JM, Jagger CJ, Chambers TJ, Chow JWM (1995) Increased insulin-like growth factor I mRNA expression in rate osteocytes in response to mechanical stimulation. Am J Physiol Endocrinol Metab 268: E318-E327.

Leri A, Caludio PP, Li Q, Wang X, Reiss K, Wang S, Malhotra A, Kajstura J, Anversa P (1998) Stretch-mediated release of angiotensin II induces myocyte apoptosis by activating p53 that enhances the local renin-angiotensin system and decreases the Bcl-2-to-Bax protein ratio in the cell. J Clin Invest 101: 1326-1342.

Li J, Mashiba T, Burr DB (2001) Bisphosphonate treatment suppresses not only stochastic remodeling but also the targeted repair of microdamage. Calcif Tissue Int 69: 281-286.

Lozupone E, Palumbo C, Favia A, Ferretti M, Palazzini S, Cantatore FP. (1996) Intermittent compressive load stimulates osteogenesis and improves osteocyte viability in bones cultured "in vitro". Clin Rheumatol. 15: 563-72.

Luciani MF, Chimini G (1996) The ATP binding cassette transporter $\mathrm{ABC} 1$, is required for the engulfment of corpses generated by apoptotic cell death. EMBO J 15: 226235.

Maejima-Ikeda A, Aoki M, Tsuritani K, Kamioka K, Hiura K, Miyoshi T, Hara H, Takano-Yamamoto T, Kumegawa M (1997) Chick osteocyte-derived protein inhibits osteoclastic bone resorption. Biochem J 15: 245 250 .

Marotti G, Farneti D, Remaggi F, Tartari F (1998) Morphometric investigation on osteocytes in human auditory ossicles. Ann Anatomy 180: 449-453.

Martin LJ (2001) Neuronal cell death in nervious system development, disease and injury. Int J Mol Med 7: 455478.
Mashiba T, Hirano T, Turner CH, Forwood MR, Johnston CC, Burr DB (2000) Suppressed bone turnover by bisphosphonates increases microdamage accumulation and reduces some biomechanical properties in dog rib. Bone Miner Res 15: 613-620.

Mashiba T, Turner CH, Hirano T, Forwood MR, Jacob DS, Johnston CC, Burr DB (2001) Effects of high-dose etidronate treatment on microdamage accumulation and biomechanical properties in beagle bone occurrence of spontaneous fractures. Bone 29: 271-278.

Mason DJ, Suva LJ, Genever PG, Patton AJ, Steuckle S, Hillam RA, Skerry TM (1997) Mechanically regulated expression of a neural glutamate transporter in bone: A role for excitatory amino acids as osteotropic agents? Bone 20: 199-205.

Matsumoto T, Nakayama K, Kodama Y, Fuse H, Nakamura T, Fukumoto S (1998) Effect of mechanical unloading and reloading on periosteal bone formation and gene expression in tail-suspended rapidly growing rats. Bone 22: 89S-93S.

McBryde AM (1975) Stress fractures in athletes. J Sports Med 3: 212-217.

McNeill PL (2002) Repairing a torn cell surface: make way, lysosomes to the rescue. J Cell Sci 115: 873-879.

McNeill PL, Steinhardt RA (1997) Loss restoration and maintenance of plasma membrane integrity. J Cell Biol 137: $1-4$.

Meier P, Finch A, Evan G (2000) Apoptosis in development. Nature 407: 796-801.

Mevorach D, Mascarenhas JO, Gershov D, Elkon KB (1998) Complement-dependent clearance of apoptotic cells by human macrophages. J Exp Med 188: 2313-2320.

Moffatt OD, Devitt A, Bell ED, Simmons DL, Gregory CD (1999) Macrophage recognition of ICAM-3 on apoptotic leukocytes. J Immunol 162: 6800-6810.

Monroe DG, Jin DF, Sanders MM (2000) Estrogen opposes the apoptotic effects of bone morphogenetic protein 7 on tissue remodeling. Mol Cell Biol 20: 4626-4634.

Mori S, Burr DB (1993) Increased intracortical remodeling following fatigue damage. Bone 14: 103-109.

Mori S, Harruff R, Ambrosius W, Burr DB (1997) Trabecular bone volume and microdamage accumulation in the femoral heads of women with a without femoral neck fractures. Bone 21: 521-526.

Muir P, Johnson KA, Ruaux-Mason CP (1999) Microdamage in a naturally occurring canine fatigue fracture. Bone 25: 571-576.

Mullender MG, Huiskes R, Versleyen H, Buma P (1996a) Osteocyte density and histomorphometric parameters in cancellous bone of the proximal femur in five mammalian species. J Orthop Res 14: 972-979.

Mullender MG, van der Meer DD, Huiskes R, Lips P (1996) Osteocyte density changes in aging and osteoporosis. Bone 18: 109-113.

Nguyen-Ba G, Vasseur P (1999) Epigenetic events during the process of cell transformation induced by carcinogens. Oncol Rep 6: 925-932.

Noble BS, Stevens H, Loveridge N, Reeve J (1997a) Identification of apoptotic changes in osteocytes in normal and pathological human bone. Bone 20: 273-282. 
Noble BS, Stevens H, Mosley JR, Pitsillides AA, Reeve J, Lanyon L (1997b) Osteocyte apoptosis and functional strain in bone. J Bone Miner Res 12: 5.

Noble BS, Peet N, Stevens HY, Brabbs A, Mosley JR, Reilly GC, Reeve J, Skerry TM, Lanyon LE (2003) Mechanical loading: biphasic osteocyte survival and targeting of osteoclasts for bone destruction in rat cortical bone. Am J Physiol Cell Physiol 284: C934-C943.

Norman TL, Wang Z (1997) Microdamage of human cortical bone: incidence and morphology in long bones. Bone 20: 375-379.

Norrdin RW, Kawcak CE, Capwell BA, Mcilwraith CW (1998) Subchondral bone failure in an equine model of overload arthrosis. Bone 22: 133-139.

Nunamaker DM, Butterweck DM, Provost MT (1990) Fatigue fractures in thoroughbred racehourses: relationships with age, peak bone strain and training. J Orthop Res 8: $604-611$.

Parfitt AM (1994) The two faces of growth: benefits and risks to bone integrity. Osteoporosis Int 4: 382-398.

Parfitt AM (2001) Trageted and non targeted bone remodeling: Relationship to BMU origination and progression. Bone 30: 585-587.

Pelengaris SA, Evan GI (1997) Matters of life and cell death. Rev Neurol (Paris) 153: 470-477.

Pitsillides AA, Rawlings SCF, Suswillo RFL, Bourrin S, Zaman G, Lanyon LE (1995) Mechanical strain-induced NO production by bone cells: A possible role in adaptive bone (re)modeling? FASEB J 9: 1614-1622.

Rawlinson SCF, Mosley JR, Suswillo RFL, Pitsillides AA, Lanyon LE (1995) Calvarial and limb bone cells in organ and monolayer culture do not show the same early responses to dynamic mechanical strain. J Bone Miner Res 10: 1225-1232.

Reilly GC, Currey JD (2000) The effects of damage and microcracking on the impact strength of bone. J Biomech 33: 337-43.

Ripps H (2002) Cell death in retinitis pigmentosa: gap junctions and the 'bystander' effect. Exp Eye Res 74: 327 336.

Rodan GA, Martin TJ (2000) Therapeutic approaches to bone diseases. Science 1: 1508-1514.

Rosen CJ (2000) Pathogenesis of osteoporosis. Baillieres Best Pract Res Clin Endocrinol Metab 14: 181193.

Rubartelli A, Foggi A, Zocchi MK (1997) The selective engulfment of apoptotic bodies by dendritic cells is mediated by the avb3 integrin and requires intracellular and extracellular calcium. Eur J Immunol 27: 1893-1900.

Sanson M, Marcaud V, Robin E, Valery C, Sturtz F, Zalc B (2002) Connexin 43-mediated bystander effect in two rat glioma cell models. Cancer Gene Ther 9: 149-155.

Savill J, Fadok V (2000) Corpse clearance defines the meaning of cell death. Nature 407: 784-788.

Schaffler MB, Radin EL, Burr DB (1989) Mechanical and morphological effects of strain rate on fatigue of compact bone. Bone 10: 207-214.

Schaffler MB, Choi K, Milgrom C (1995a) Ageing and matrix microdamage accumulation in human compact bone. Bone 17: 521-525.
Schaffler MB, Boyce TM, Lundin-Cannon KD, Milgrom C, Fyhrie DP (1995b) Age related architectural changes and microdamage accumulation in the human femoral neck cortex. Trans Orthop Res Soc 20: 549.

Shibahara M, Nishida K, Asahara H, Yoshikawa T, Mitani S, Kondo Y, Inoue H (2000) Increased osteocyte apoptosis during the development of femoral head osteonecrosis in spontaneously hypertensive rats. Acta Med Okayama 54: 67-74.

Silvestrini G, Ballanti P, Patacchioli FR, Mocetti P, Di Grezia R, Wedard BM, Angelucci L, Bonucci E (2000) Evaluation of apoptosis and the glucocorticoid receptor in the cartilage growth plate and metaphyseal bone cells of rats after high-dose treatment with corticosterone. Bone 26: 33-42.

Stern M, Savill J, Haslett C (1996) Human monocytederived macrophage phagocytosis and senescent eosinophils undergoing apoptosis: mediation by avb3/CD36 thrombospondin recognition mechanism and lack of phlogistic response. Am J Pathol 149: 911-921.

Sun Y-Q, McLeod KJ, Rubin CT (1995) Mechanically induced periosteal bone formation is paralleled by the upregulation of collagen type one mRNA in osteocytes as measured by in situ reverse transcript-polymerase chain reaction. Calcif Tissue Int 57: 456-462.

Taylor D (1998) Fatigue of bone and bones: An analysis based on stressed volume. J Orthop Res 16: 163-169.

Taylor PR, Carugati A, Fadok VA, Cook HT, Andrews M, Carroll MC, Savill JS, Henson PM, Botto M, Walport MJ (2000) A hierarchical role for classical pathway complement proteins in the clearance of apoptotic cells in vivo. J Exp Med 192: 359-366.

Tesarik J, Maretinez F, Rienzi L, Iacobelli M, Ubaldi F, Mendoza C, Greco E (2002) In vitro effects of FSH and testosterone withdrawal on caspase activation and DNA fragmentation in different cell types of human seminiferous epithelium. Hum Reprod 17: 1811-1819.

Tomkinson A (1998) Effects of oestrogen on the maintenance of bone mass and bone cell viability. PhD Thesis Cambridge University.

Tomkinson A, Reeve J, Shaw RW, Noble BS (1997) The death of osteocytes via apoptosis accompanies estrogen withdrawal in human bone. J Clin Enocrinol Metab 82, 3128-3135.

Tomlin JL, Lawes TJ, Blunn GW, Goodship AE, Muir P (2000) Fractographic examination of racing greyhound central (navicular) tarsal bone failure surfaces using scanning electron microscopy. Calcif Tissue Int 67: 260-266.

Tremollieres FA, Pouilles JM, Ribot C (2001) Withdrawal of hormone replacement therapy is associated with significant vertebral bone loss in postmenopausal women. Osteoporosis Int 12: 385-390.

Ueki A, Isozaki Y, Tomokuni A, Hatayama T, Ueki H, Kusaka M, Shiwa M, Arikuni H, Takeshita T, Morimoto K (2002) Intramolecular epitope spreading among anticaspase- 8 autoantibodies in patients with sclerosis and systemic lupus erythematosus, as well as in healthy individuals. Clin Exp Immunol 129: 556-561.

Verborgt O, Gibson GJ, Schaffler MB (2000) Loss of osteocyte integrity in association with microdamage and 
bone remodeling after fatigue in vivo. J Bone Miner Res 15: 60-67.

Voll RE, Herrmann M, Rothe EA, Stach C, Kalden JR (1997) Immunosuppressive effects of apoptotic cells. Nature 390: 350-351.

Wang R, Zagariya A, Ang E, Ibarra-Sunga O, Uhal BD (1999) Fas-induced apoptosis of alveolar epithelial cells requires ANG II generation and receptor interaction. Am J Physiol 277: 1245-1250.

Warden SJ, Gutschlag FR, Wajswelner H, Crossley KM (2002) Aetiology of rib stress fractures in rowers. Sports Med 32: 819-836.

Weinstein RS, Jilka RL, Parfitt AM, Manolagas SC (1998) Inhibition of osteoblastogenesis and promotion of apoptosis of osteoblasts and osteocytes by glucocorticoids. Potential mechanisms of their deleterious effects on bone. J Clin Invest 102: 274-282.

Weinstein RS, Nicholas RW, Manolagas SC (2000) Apoptosis of osteocytes in glucocorticoid-induced osteonecrosis of the hip. J Clin Enocrinol Metab 85: 29072912.

Wong SY, Kariks J, Evans RA, Dunstan CR, Hills E (1985) The effect of age on bone composition and viability in the femoral head. J Bone Joint Surg Am 67: 274-283.

Wu YC, Horvitz HR (1998) The C. elegans cell corpse engulfment gene ced-7 encodes a protein similar to ABC transporters. Cell 93: 951-960.

Wyllie AH (1997) Apoptosis: an overview. Br Med Bull 53: 451-465.

Wyllie AH, Kerr JF, Currie AR (1980) Cell death: the significance of apoptosis. Int Rev Cytol 68: 251-306.

Yang P, Chen L, Zhou H, Zhong H, Wang H, Huang X, Kijlstra A (2002) Resistance of lymphocytes to Fas-mediated apoptosis in Behcet's disease and Vogt-KoyangiHarada syndrome. Ocul Immunol Inflamm 10: 47-52.

Zhao S, Zhang YK, Harris S, Ahuja SS, Bonewald LF (2002) MLO-Y4 osteocyte-like cells support osteoclast formation and activation. J Bone Miner Res 17: 2068-2079.

\section{Discussion with Reviewers}

M. Alini: Are there any alternative hypotheses in the field to explain why resorption is elevated in areas of microfractures?

Author: Alternative hypotheses based on cells remaining alive and signaling specifically for osteoclast invasion have been based on the ability of osteocyte cell lines to synthesise and export molecules capable of enhancing osteoclastic formation and function (Zhao et al., 2002, text reference). It is clear that the cell line is capable of producing such molecules that may have physiological relevance under certain conditions. However, the recent discovery by 2 independent groups that the induction of microdamage in bone is associated not with live cells but with the apoptotic death of osteocytes would tend to implicate cell death at some level in the targeting of damage. It is possible that either the dying cell first upregulates its production of proresorptive molecules or that signals associated with death enhance production of pro-resorptive signals in neighbouring cells.

The possibility that the loss of an osteocyte derived antiresorptive signal allows influx of osteoclasts is less likely since the lack of osteocytes in general is linked to less resorption and not more (see details in review).

My laboratory is engaged in research aimed at characterizing the signals involved in the targeting process. Overall I feel that our hypothesis is currently the strongest but as ever time and research effort will determine the importance of the phenomenon in bone health.

M. Alini: Could you speculate about possible molecules involved in the potential molecular links between damage induced apoptosis and targeted osteoclast activity and why they may be involved?

Author: Speculation regarding the identity of molecules involved in the signaling between damage located osteocytes and osteoclasts is inappropriate at this time since it is the subject of impending publications from my laboratory. In general we might consider candidate signal molecules to be either associated with apoptotic recognition and phagocytosis, those known to be important in osteoclastogenesis and function or "other" novel signals. Which is another way of saying it could be anything! The question is of course a very important one and I hope that we will answer it in subsequent publications.

R.G. Richards: Does the author believe that osteoclasts may be stimulated directly by micro-cracks evoking an inflammation to the damaged bone surface or just indirectly by factors that are produced by the apopotic osteocytes.

Author: I am not sure I understand this question. Are you proposing an inflammatory response without the involvement of cells? I do suspect the signal is indirect rather than directly from the crack itself although one might consider the possibility that the osteoclast can sense crack derived bone particles along the lines of "wear debris" or the energy change or "sound" associated with a crack although no evidence exists to support such hypotheses. The possibility that an "inflammation like" response is engendered by the damage would almost certainly involve cellular products in some way and is therefore related to our proposed hypotheses although inflammatory responses are more likely to be initiated by necrotic rather than apoptotic debris. 